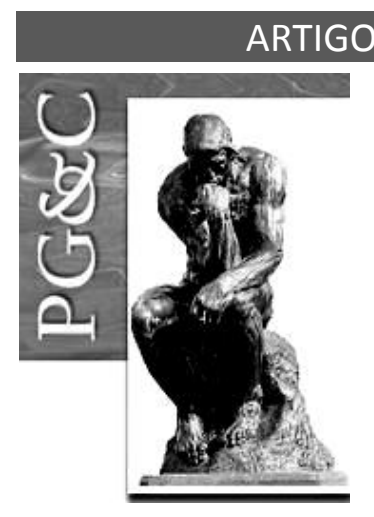

\title{
MATERNIDADE EM PAUTA: REFLEXÕES SOBRE ATIVISMO DIGITAL E SUA RELAÇÃO COM A COMPETÊNCIA EM INFORMAÇÃO
}

\author{
Lílian Viana Teixeira Cananéa \\ Doutoranda em Ciência da Informação pela Universidade Federal \\ da Paraíba, Brasil. Professora da Universidade Federal da Paraíba, Brasil. \\ E-mail: lilianviana.professora@gmail.com \\ Maria Meriane Vieira Rocha \\ Doutoranda em Ciência da Informação pela Universidade Federal da \\ Paraíba, Brasil. Professora da Universidade Federal da Paraíba, Brasil. \\ E-mail: meriane.vieira@gmail.com \\ Maria das Graças Targino \\ Doutora em Ciência da Informação pela Universidade de Brasília, Brasil. Professora \\ da Universidade Federal do Piauí, Brasil. \\ E-mail: gracatargino@hotmail.com
}

\begin{abstract}
Resumo
Objetiva discutir o ativismo digital materno no que concerne aos benefícios quanto às novas formas de ação e de lutas por meio da cibercultura. O foco é apresentar a mobilização de mulheres-mães como movimento social em rede, que se apropria das potencialidades da internet para propor olhar inovador sobre a maternidade na vida contemporânea. Como decorrência, o artigo relaciona ativismo digital $x$ competência informacional como agente propulsor de engajamento dos atores sociais, o que resulta em revisão de literatura, que incorpora os itens: identidade da mulher-mãe e sua ressignificação frente ao ativismo digital; e competência em informação, com ênfase para o papel da mulher-mãe no âmbito da Ciência da Informação. Em termos metodológicos, configura-se como pesquisa bibliográfica, que favorece informar ao pesquisador o status quo da temática central: maternidade e ativismo digital. 0 estudo também é descritivo, exploratório e qualitativo. Descritivo, pois se limita a descrever, registrar, analisar e interpretar fatos ou fenômenos da realidade, sem qualquer interveniência. No caso da pesquisa exploratória, seu intuito é favorecer visão genérica de determinadas questões de pesquisa, em geral, temas pouco explorados. Por fim, a pesquisa qualitativa privilegia particularidades e experiências individuais e grupais, haja vista que seu alvo é apreender o comportamento de determinado grupo social. No caso, as inferências confirmam a presença crescente das mulheres-mães nas redes sociais recorrendo às tecnologias como ferramenta para colocar a maternidade em pauta.
\end{abstract}

Palavras-chave: Maternidade. Cibercultura. Ativismo digital. Plataforma digital. Competência em Informação.

MATERNITY ON THE PATTERN:

REFLECTIONS ON DIGITAL ACTIVISM AND ITS RELATIONSHIP WITH THE INFORMATION COMPETENCE

\begin{abstract}
The objective is to discuss the maternal digital activism regarding the benefits resultant from new forms of action and campaigns using the cyber culture. The focus is to present the mothers mobilization as social network movements, by taking advantage of the internet potential to propose an innovative look at the motherhood in contemporary life. As a result, the paper correlates the digital activism and
\end{abstract}

Perspectivas em Gestão \& Conhecimento, João Pessoa, v. 8, n. 3, p. 20-39, set./dez. 2018. DOI: http://dx.doi.org/10.21714/2236-417X2018v8n3p20

http://periodicos.ufpb.br/ojs2/index.php/pgc. ISSN: 2236-417X. Publicação sob Licença (cc) EY-NC-ND 
informational competence as a propelling agent for the engagement of social actors. Therefore, the literature review incorporates the following items: the identity of mothers and their resignification towards the digital activism; and information competence, with emphasis on the role of the mothers in the field of Information Science. In methodological terms, it is a bibliographical research, which provides information to the researcher about the status quo of the central subject: motherhood and digital activism. The study is also descriptive, exploratory and qualitative. Descriptive, because it is limited to describing, recording, analyzing and interpreting the reality facts without any intervention. It constitutes exploratory research, because it aims to provide a generic vision of certain research questions, which are, in general, underexplored subjects. Finally, this qualitative research focuses on particularities and on individual and group experiences, since its aim is to approach the behavior of a certain social group. In this case, the inferences confirm the increasing presence of mothers in social networks where they use technologies as a strategy to include maternity in the agenda. This requires the adoption of public policies in favor of these women in order to make this information competence reachable by other mothers.

Keywords: Motherhood. Cyber culture. Digital activism. Digital platform. Information competence.

\section{INTRODUÇÃO}

A mãe é aquele bloco informe e sem face, para o qual ninguém olha; ele não assinala nada, não significa nada e apenas tem a função de manter, sustentar, realçar e glorificar a estátua definitiva - o filho.

(Heloneida Studart, 1990)

É por meio dos valores sociais, determinados pela visão de mundo de grupos sociais, que fatos, fenômenos, objetos, comportamentos e interações ganham significado, fundamentando a sempre polêmica concepção de ética e/ou moral dos indivíduos que integram o coletivo. Como decorrência, os comportamentos tornam-se padrões a serem internalizados e naturalizados pelos integrantes das coletividades, independentemente de gênero, faixa etária e posição hierárquica no núcleo familiar e societal. Os valores subjacentes aos agrupamentos sociais permitem classificar e hierarquizar as condutas dos indivíduos em diferentes setores da vida e da interação social. Desta forma, algumas ações são consideradas "justas e corretas", e, portanto, devem ser incentivadas, enquanto outras passam a ser consideradas "amorais, imorais e/ou incorretas", devendo, portanto, ser vetadas, obviamente, a depender da cultura vigente nos diferentes países.

O Programa das Nações Unidas para o Desenvolvimento, ainda na década de 90, século XX, afirma literalmente, o que, decerto, ainda representa, em sua essência, a realidade de nossos dias, com dados ainda mais promissores:

De modo geral, as mulheres representam cerca de $30 \%$ do esforço de produção de conhecimentos científicos e tecnológicos no país. Correspondem a $31 \%$ dos pesquisadores com bolsas, respondendo por $32 \%$ dos recursos humanos em ciência e ensino cadastrados pelas agências gestoras da política de ciência e tecnologia. São autoras de 32\% dos artigos publicados em revistas nacionais e de $27 \%$ dos divulgados em periódicos internacionais; são responsáveis por 30\% dos livros publicados, $32 \%$ dos trabalhos apresentados em congressos e $32 \%$ das teses defendidas no país. São mulheres $37 \%$ dos mestrandos e $34 \%$ dos doutorandos com bolsas no exterior (PNUD, 1996, p. 38).

Perspectivas em Gestão \& Conhecimento, João Pessoa, v. 8, n. 3, p. 20-39, set./dez. 2018. 
É o reconhecimento do papel crescente da mulher na sociedade contemporânea, com atuação marcante no mercado de trabalho, em profissões variadas, no exército, na astronomia, nos esportes, nas universidades, na literatura, na música, nos bares, no teatro, na aviação, na cozinha, enfim, vivenciando a condição de uma nova mulher na tessitura social. Trata-se de assertiva em torno de que a mulher nem pode ser omissa, nem tampouco relegar seu papel de agente social, como mãe, filha, mulher, companheira, amante, avó, tia, amiga, profissional, etc. etc. A mulher precisa afrontar a vida, a cada dia, mas este enfrentamento e esta luta devem representar um caminhar ao lado do homem, numa ação nitidamente complementar, em que as diferenças são respeitadas e a unicidade é mais do que nunca acatada.

No entanto, paradoxalmente, Berger e Luckmann (2004) denunciam certo repúdio da sociedade, com frequência, implícito e/ou nas entrelinhas, em pleno século XXI, em relação às mulheres que investem na carreira de forma prioritária e, quando mães, tendem, por exemplo, a enviar mais cedo os filhos para os berçários, contradizendo as expectativas tradicionais em torno da mulher-mãe: cuidar da casa, do esposo e dos filhos. Para elas, sobram adjetivos condicionados pela estrutura social, como: "mães desalmadas", "mães sem coração" e feminazi, este último termo adotado de forma pejorativa para designar mulheres consideradas radicais nas questões de igualdade de gênero.

Partindo desse pressuposto da cultura das relações de gênero, o referido artigo objetiva discutir a luta pela ressignificação da identidade materna contemporânea, por meio do ativismo digital, além de relacionar o movimento com a competência em informação, na esfera da Ciência da Informação (Cl), como estratégia vital para fortalecer e ampliar o engajamento dos atores sociais em prol da mudança de identidade do ser mãe.

Com a rápida expansão das redes eletrônicas de informação e de comunicação, ênfase para a internet, a era da tecnocultura via comunicação mediada por computador vem desempenhando papel estratégico no processo identitário, segundo Sodré (2013) evidencia. Ademais, o neologismo cibercultura especifica o conjunto de técnicas materiais e intelectuais voltadas a práticas, atitudes, modos de pensamento e de valores que se desenvolvem juntamente com o crescimento do ciberespaço (LÉVY, 2000). Há, pois, flagrante chance de debates e posicionamento público dos agentes sociais, os quais alimentam o ativismo de mulheres com filhos.

Isto é, a cultura da participação (JENKINS, 2009) e a inteligência coletiva (LÉVY, 2000) atuam como ferramentas para redes eletrônicas que unem mulheres-mães. Tais mulheres "bebem" na fonte da quarta "onda" do feminismo via redes sociais e trazem para a sociedade debates, antes restritos à esfera privada, como Hall (2006) enfatiza. Isto é, uma extensão desse coletivo debruça-se sobre questões que norteiam a condição social da maternidade na sociedade neoliberal, o que corresponde à análise de temática de interesse para a gestão e o conhecimento sob uma abordagem que propicie contribuição para temas pouco explorados no campo da $\mathrm{Cl}$, com nítidas chances de diálogos interdisciplinares, pluridisciplinares, multidisciplinares e, portanto, também transdisciplinares.

Diante disso, o paper segue este questionamento: de que forma as mulheres com filhos experimentam o fortalecimento e a expansão de debates sobre a maternidade, com o uso da plataforma digital? Em termos de hipótese central, acredita-se que o ativismo digital materno consiste em estratégia preciosa de mudança da imagem da mulher-mãe. No espaço virtual, a maternidade vem sendo colocada em pauta e as mulheres vêm provocando discussões importantes sobre as mais diversas questões: o conceito da maternidade em si; a conjunção maternidade $x$ trabalho; a divisão de tarefas no núcleo familiar, dentre outros itens.

Porém, a divulgação ampla requer engajamento, não apenas de mães, mas de mulheres sem filhos (por opção ou não) e homens, com ou sem filhos. Como adendo, acrescenta-se que, em agosto de 2017, a Folha de S. Paulo elabora um caderno digital especial

Perspectivas em Gestão \& Conhecimento, João Pessoa, v. 8, n. 3, p. 20-39, set./dez. 2018. 
em homenagem a homens que se tornaram mães, por razões diversificadas: são os chamados "pães" (pai e mãe). A reportagem especial, dedicada aos "Dia dos Pais", sob encargo de Flores e Balago (2017), reverencia cinco "pães" por suas maiores paixões: Jota, deslumbrado por aventuras; Jair, amante de motocicletas; Sandro, atleta; Rodrigo, cuidador de plantas; e Wilson, ouvinte de heavy metal. Cada página enfatiza o hobby dos pais, com a justificativa de que, em meio aos cuidados com os filhos, eles precisam de descanso.

Em maio do mesmo ano, no mesmo jornal, a repórter Ana Ribeiro (2017) homenageia as mulheres com filhos por meio de menção a cinco paulistanas. Em vez de caderno especial, a matéria privilegia as mais significativas conquistas emocionais das mulheres ao se tonarem mães. Não há alusão a hobbies. O cerne é o instinto materno, em torno de filhos biológicos e/ou adotivos com os sacrifícios inerentes ao papel de "rainha do lar." O fazer jornalístico também deixa transparecer a identidade da mulher-mãe, construída e enraizada ao longo dos anos pela formação patriarcal da família. Eis um ser invisível, cuja maternidade é a finalidade máxima e, então, sem demanda de enaltecimento. À mulher, cabe agir conforme os padrões para encontrar marido e, por fim, procriar. Aos homens, cabem invenções, desenvolvimento e controle da família, remontando a tempos longínquos, quando o

[...] grande handicap da mulher foi um fato histórico. Aconteceu quando o homem saiu à caça e ela se deixou ficar na caverna, cozinhando e procriando, em plena vegetatividade. O homem lutou, cresceu, criou [...] A ação assegurou seu desenvolvimento mental. Enquanto isto, a mulher sempre na caverna (que passou a se chamar de lar) esperava, imutavelmente, a volta do caçador (STUDART, 1990, p. 10).

São pensamentos que contrariam frontalmente Elisabeth Badinter, que, em polêmica tese de doutoramento, transformada em livro sob o título "L'amour en plus", 2000, argumenta que o amor maternal é, sobretudo, um amor conquistado e, em sua essência, meramente cultural e imbuído de mitos. Por tudo isso, é essencial que as ativistas, à frente das discussões, possuam competência para trabalhar a informação, de maneira adequada, com o intuito de aperfeiçoar, adiante, a gestão do fluxo informacional e do conhecimento. É preciso extremo cuidado na seleção das informações postas em circulação, o que significa pesquisar, filtrar e divulgar o que é relevante, fidedigno e credível, para não ingressar no universo das propaladas fake news, expressão em voga para denunciar inverdades e crendices que rondam o universo das redes sociais, apesar de ser possível contestar a própria expressão - se é fake, significa dizer que é inidôneo, e, por conseguinte, não se coaduna com o conceito de news como notícia, então, presumidamente verdadeira.

A este respeito, é interessante o ponto de vista do norte-americano Andrew Keen, cuja obra "The cult of the amateur: how today's internet is killing our culture", a partir do próprio título e subtítulo, alerta para os riscos do enaltecimento da internet na vida do homem contemporâneo. Ele mesmo, um dos pioneiros das corridas iniciais de ouro da Rede, hoje, admite que as tecnologias usadas de forma abusiva destroem economia, cultura e valores. São ações que comprometem a produção intelectual, científica e acadêmica da humanidade. $O$ fornecimento excessivo de conteúdos duvidosos provenientes de fontes, muitas vezes, anônimas, sequestram o tempo do indivíduo, roubam energia em busca de suprir suas demandas informacionais, e, mais do que tudo, dilaceram a credulidade das informações. A permissividade do anonimato e a prevalência do amadorismo em detrimento do aprofundamento das informações e dos conhecimentos estão gerando desinformação e flagrantes mentiras que se espalham a passos de gigante, reafirmando a premissa do exprimeiro-ministro britânico James Callaghan, segundo a qual "uma mentira pode dar a volta ao

Perspectivas em Gestão \& Conhecimento, João Pessoa, v. 8, n. 3, p. 20-39, set./dez. 2018. 
mundo antes que a verdade tenha a chance de calçar as botas" (KEEN, 2009, p. 22), o que põe em evidência se investir maciçamente na gestão da informação cibernética.

Consequentemente, as ativistas que lutam para pautar a maternidade por meio do ativismo digital, devem primar por sua relação com a competência em informação (Colnfo), em termos de conteúdos válidos e valiosos. Além disso, precisam saber utilizar a linguagem adequada para cada rede social e público específico. Com a conjunção (competência em informação + ativismo), é possível modificar a imagem sobre a maternidade e conseguir agregar mais pessoas à luta das mulheres-mães e profissionais. Reitera-se que a relevância do tema vincula-se ao estudo das relações entre os discursos sobre possíveis perspectivas ou pontos de acesso de variadas comunidades de usuários, um dos campos da $\mathrm{Cl}$, conforme Capurro (2003) destaca. Entre essas comunidades, Espírito Santo (2008, p. 318) destaca as mulheres-mães, como "[...] grupo sincronizado em linguagem e conhecimento e construído socialmente atrelado a dimensões culturais, sociais e históricas."

Em termos estruturais, o artigo, além da introdução, distribui-se em mais quatro seções. Na seguinte, aponta os caminhos metodológicos. A terceira, por sua vez, delineia aspectos acerca do surgimento e das características gerais da identidade da mulher-mãe no decorrer do desenvolvimento e do fortalecimento da sociedade patriarcal, para, na sequência, discorrer sobre a apropriação do universo digital pela mulher-mãe, como nova frente para potencializar suas pelejas na esfera pública e privada. Na quarta grande seção, discorre-se sobre a competência em informação e sua relação com o engajamento na luta pelo novo olhar sobre o ser mãe, seguindo-se as considerações finais e a listagem de fontes consultadas para a construção do texto.

\section{CAMINHOS METODOLÓGICOS}

Considerando a inexistência de categorização consensual quanto à tipologia de pesquisas científicas, as quais, mais e mais, exigem a combinação de métodos e técnicas, a pesquisa em pauta configura-se, a priori, como bibliográfica e descritiva. No primeiro caso, trata-se de conjunção de procedimentos para identificar, selecionar, localizar e obter fontes de interesse para a consecução dos objetivos propostos, o que envolve técnicas de leitura e transcrição de dados que permitem recuperá-los, sempre que necessário, de acordo com transcrição exaustiva de Stumpf (2008). Acrescenta-se que a pesquisa bibliográfica trata do levantamento de fontes bibliográficas e/ou eletrônicas com o fim de colocar o pesquisador em contato direto com o que foi escrito até então sobre a temática - mulheres-mães; ativismo digital e competência em informação - favorecendo sua análise sob novo enfoque.

Indo além, o estudo também é categorizado como descritivo, exploratório e qualitativo. A pesquisa descritiva, no rastro da própria designação, limita-se a abordar quatro aspectos - descrição, registro, análise e interpretação de fatos ou fenômenos de determinada realidade - sem manipulá-los, ou seja, sem exercer qualquer interveniência. Em se tratando da pesquisa exploratória, o intuito central é favorecer visão genérica de determinado tema, do tipo aproximativo, de modo a tornar o objeto de estudo e a formulação das hipóteses centrais ou adjacentes mais visíveis (GIL, 2010). A pesquisa exploratória é realizada sobre um problema ou questões de pesquisa, geralmente, com pouco estudo anterior ao seu respeito. A qualitativa privilegia particularidades e experiências individuais e grupais, haja vista que seu alvo é apreender o comportamento de determinado grupo social, no caso, as mulheres-mães.

\section{IDENTIDADE DA MULHER-MÃE}

Segundo Fidalgo (2003), por mais que soe estranho, na Pré-História, período que antecede o aparecimento da escrita e corresponde à prevalência de ferramentas de pedra e,

Perspectivas em Gestão \& Conhecimento, João Pessoa, v. 8, n. 3, p. 20-39, set./dez. 2018. 
mais adiante, dos metais - Período Paleolítico (Idade da Pedra Lascada); Período Neolítico (Idade da Pedra Polida); Idade dos Metais (Ferro, Cobre e Bronze) - embora varie de região para região (estima-se que as primeiras ferramentas de pedra surgem há, aproximadamente, três milhões de anos, no continente africano), a imagem da mulher-mãe aparece impregnada de importância e adoração. Cuidado e sobrevivência das crianças são, então, responsabilidade única das fêmeas. Sua habilidade na partilha de alimentos mostra-se essencial para a perpetuação da espécie e, por isso, sua função é venerada por todos. Dar à luz e conservar a prole consiste em tarefa que exerce flagrante diferença na organização social da época:

Nesse longínquo começo, a mãe da espécie humana não foi só figura temida e reverenciada pela misteriosa capacidade de engendrar crianças, mas também pelo seu saber, o da experiente colectora de alimentos que sabiamente definia os padrões de partilha dos mesmos. A mulher pagã, representada com formas protuberantes, ou de ventre liso, geradora e guerreira, é sempre poder (FIDALGO, 2003, p. 86).

$\mathrm{Na}$ fase da história propriamente dita, desde a Idade Antiga, período iniciado com as mais antigas civilizações e que vai até a queda do Império Romano do Ocidente (século V), a identidade da mulher-mãe passa a ser construída pelo discurso masculino. Sua repetição, ao longo do tempo, alicerçada por elementos diversificados, como religião, arte e sistema capitalista, reforça a cultura ocidental de desvalorização das mulheres, em especial das mães, colocando-as como serviçais dos homens e a quem compete exercer a maternidade por obrigação, tornando-as invisíveis no espaço público e, em situação subalterna, no espaço privado do lar.

Em outras palavras, o poder da mulher esvai-se para dar lugar à institucionalização do patriarcado, regime social em que o homem atua com autoridade preponderante, cerca de seis mil anos atrás, momento em que sua propagação ganha forma com a concepção do paternalismo, termo de origem grego e que significa, literalmente, "a regra do pai", ou "chefe de uma raça." Em linhas gerais e práticas, o patriarcado é um sistema social em que os homens mantêm poder e liderança na política, no controle das propriedades e na determinação dos valores morais. Na família, sua figura mantém autoridade sobre mulheres e filhos. Como decorrência, a partir de então, a fêmea deixa de assumir a mesma importância do homem e seu papel e sua função passam a ser definidas pelo poder masculino, que impõe a subordinação feminina como imperativo em prol da harmonia da estrutura social.

Como primeira prestadora de cuidados, virá a ser impedida a cuidar ou a rejeitar, a embalar ou a evitar o contato com a criança, consoante decisão patriarcal. Desse começo, em que se vislumbrou a mais antiga concepção mítica e divinizante da mulher, passar-se-á a outra leitura, àquela em que a sobrevivência da humanidade se vai dissociando das concepções primitivas (FIDALGO, 2003, p. 87).

Eis o início do processo de invisibilidade da mulher-mãe, fortalecido por pensadores da Grécia Antiga, a exemplo de Aristóteles, filósofo grego, o qual, junto com Platão e Sócrates é considerado como um dos fundadores da filosofia ocidental, mas para quem a participação da mulher na vida pública configura-se como risco à harmonia social e, portanto, deve ser evitada. Aos homens, cabem as atividades nobres da arte, da política e da guerra, em detrimento das mulheres, consideradas inferiores e desprovidas de razão e pensamento crítico. "Vendidas" pelo pai - mediante a concessão de dotes -, a mulher perde autonomia de decidir seu futuro. Limita-se a obedecer, em silêncio, ao homem que lhe comprou, qual seja, o marido / novo proprietário de seu destino. Nem a maternidade, função exclusiva do sexo feminino, tem relevância. Ao homem, responsável pelo controle e pela estrutura da família, compete, ainda, decidir os filhos que vão ser criados ou rejeitados pela mulher.

Perspectivas em Gestão \& Conhecimento, João Pessoa, v. 8, n. 3, p. 20-39, set./dez. 2018. 
Na Grécia Antiga, a representação da mãe estava praticamente afastada da arte e da religião, e até na mitologia são abundantes as maternidades masculinas, cuja prole nasce de algumas partes da autonomia do macho. Vai longe a poderosa deusa-mãe. As suas descendentes, as deusas gregas, são deusas sem mãe e dominadas pelo pai, Zeus (FIDALGO, 2003, p. 88).

Na Roma Antiga, de forma similar, a função da mãe também é restrita à maternidade. No entanto, face às elevadas taxas de mortalidade de então, as mulheres conquistam um pouco mais de espaço do que as gregas. Em Roma, inclusive, há registro de protestos junto ao Senado contra a proibição do uso de transportes pelas mulheres e a obrigatoriedade de se deslocarem a pé. No caso das excluídas do seio da família patriarcal (separadas do marido e viúvas, por exemplo), chamadas de matronas, havia a autonomia de escolher um amante, embora ele nunca pudesse se tornar, legalmente, seu esposo. Em contraposição, as senhoras detêm o poder de optar por não ter filhos, rompendo com o propósito maior imposto socialmente, à época.

Na Idade Média, entre o começo do século $V$ e meados do século $X V$, o exercício da maternidade servil é impulsionado pela religião, por meio da representação de Eva e Maria. A primeira, responsabilizada por toda a origem do mal da humanidade em forma de serpente, e, por isso, predestinada a sofrer as dores do parto e a constante submissão ao marido, como forma de punição e de controle. Maria, ao contrário, representa a proposta de uma nova mulher-mãe, feminina e sem pecado, de inteira sujeição voluntária ao marido, devido ao amor incondicional e não mais escravizante. Assim, a imagem da mulher-mãe transforma-se em mito do amor incondicional aos filhos, como instinto materno, justificando-se pelo ato biológico de parir. Sob esta ótica, a mulher abandona seu eu anterior e passa a desempenhar plenamente o papel de boa mãe, com sacrifícios voluntários em nome dos filhos, total abnegação e autoanulação, em prol da harmonia familiar, leiam-se, filhos e marido.

Posteriormente, na Idade Moderna, final do século XV até a Idade das Revoluções no século XVIII, registra-se um momento em que a produção artística e literária ganha tal intensidade e importância que esse período passa a ser designado como Renascimento ou Renascença, cujo berço está na península itálica, mormente, em cidades de intensa produção cultural, a exemplo de Veneza e Florença. Estende-se, aproximadamente, entre meados ainda do século XIV e fim do século XVI. No entanto, a situação das mulheres ainda é inaceitável. Além de servis, são sistematicamente perseguidas e, na melhor das hipóteses, renegadas ou relegadas, caso não sigam os padrões patriarcais estabelecidos. Nem mesmo no lluminismo, período-chave para aquisição de direitos fundamentais do indivíduo, a mulher-mãe alcança conquistas significativas. Ainda para Fidalgo (2003), a construção masculina do mundo, ao determinar as atividades inerentes às mulheres, considera a qualidade ou a condição de ser mãe, não mais como algo sublime e grandioso, mas, sim, como ocorrência constrangedora, e que transforma as mulheres como seres inaptos a cumprirem quaisquer outras tarefas, salvo os cuidados dos filhos e do marido.

Como decorrência, sem condições de assumir encargos distintos, devido ao processo biológico de dar à luz, a mulher-mãe é associada a uma imagem de fragilidade e, assim, com necessidade de proteção em seu espaço doméstico e de reclusão. Paralelamente, compete ao homem ocupar o poder do espaço público e o controle (camuflado sob o argumento de proteção) do espaço privado. E mais, com o acesso à educação negado séculos antes, 0 capitalismo lança mão desse cenário para fortificar o discurso machista. Longe da educação formal, as mulheres restringem-se a realizar cursos que as ajudem a se tornarem esposas e mães perfeitas. Aprender idiomas está também fora de cogitação, uma vez que, em sua condição de sexo frágil, correriam o risco de sucumbir à corrupção, afastando-se do papel divino de submissão à família. Em outras palavras, ao forjar um universo em estilo romântico, fundamentado em sentimentos nobres, como amor e respeito, que rondam a maternidade

Perspectivas em Gestão \& Conhecimento, João Pessoa, v. 8, n. 3, p. 20-39, set./dez. 2018. 
então exaltada pelos homens, ainda de acordo com Fidalgo (2003), o discurso vitoriano mantém e cultiva a tendência da invisibilidade da mulher.

Na Idade Contemporânea, fase histórica entre o início da Revolução Francesa, com a queda da Bastilha em 14 de julho de 1789 até os dias atuais, comemora-se mais de 50 anos da revolução feminista, que atinge seu auge, quando sua idealizadora e maior representante, Betty Friedan, autora de "The feminine mystique", 1963, luta para despertar e consolidar a ressignificação da imagem da mulher e da mãe. Eis uma das mais importantes obras do século XX em relação à mulher, com tradução numa série de idiomas, incluindo o português. É uma denúncia plena de significados, uma vez que mediante pesquisa exaustiva de campo com as mulheres da época, a norte-americana reitera que, desde a mobilização para a Segunda Guerra Mundial, a tendência é transformar meninas e adolescentes em pessoas incapazes de outras habilidades, salvo o cuidado do lar.

É preciso, assim, reconhecer os ganhos para a mulher de hoje, graças ao feminismo. Como qualquer movimento social e político, de linhas radicais, cometeu equívocos e desvios. Primeiro, ao buscar soluções únicas para questões que envolvem decisões de foro íntimo, e, portanto, são intrinsecamente imprevisíveis. O segundo ponto é a tendência para reproduzir o modelo masculino, quando, na verdade, no momento que apregoa tal igualdade, rouba da mulher, mais uma vez, sua possibilidade de escolha, até porque, no também clássico sobre a temática, "Passages: predictable crises of adult life", Gail Sheehy (1986, p. 136) afirma ser inteiramente impossível

[...] a duas pessoas coordenar (sic) todas as suas crises de desenvolvimento. A época do aparecimento das oportunidades externas quase nunca será a mesma. Mais importante do que isso, cada pessoa possui uma estrutura de vida interna, com suas próprias idiossincrasias [...] Cada um alternará de maneira diferente entre épocas de certeza absoluta, esperança e sensação de potencialidade e épocas de vulnerabilidade.

De qualquer forma, devem-se às pioneiras uma série de conquistas atuais que possibilitem condição de vida mais digna para as mulheres, mães ou não, em meio à sociedade patriarcal, detentora do discurso hegemônico machista. Dentre estas vitórias, estão: oportunidades de escolarização mais elevada e, consequentemente, melhores empregos e maior espaço no mercado de trabalho; direito ao voto; acesso ao divórcio; chance de optar pelo aborto, sobretudo, no caso das nações desenvolvidas; permissão para viver sua liberdade sexual e profissional, mediante a desconstrução de uma cultura masculina, reforçando o trecho do PNUD (1996), antes transcrito. Fica claro, então, que as mudanças para a vida do ser humano do sexo feminino decorrem de ações orquestradas em frentes variadas como, por exemplo, participação em políticas sociais e, na atualidade, bem maior vigilância no que diz respeito à violência física e psicológica, entre outras medidas.

Indo e vindo ao transcorrer de décadas e séculos, vê-se, pois, que a identidade da mulher-mãe sofre evoluções e involuções, a depender dos povos. Em termos genéricos, a imagem de abnegação da mãe "esposa de meu marido e mãe de meus filhos" (STUDART, 1990, p. 15) permanece presente e forte no cotidiano pós-moderno. Ao longo dos dias, percebe-se, ainda, a repetição de imagem de mãe subserviente por instinto biológico e amor incondicional. Um instrumento para um fim masculino que apenas reproduz os discursos de um sistema que oprime e bloqueia o valor social da maternidade.

No entanto, a bem da verdade, há teóricos contemporâneos, à semelhança da citada francesa Elisabeth Badinter (2000), para quem a mãe é personagem relativa e tridimensional. Relativa, porque só existe em função do pai e do filho. Tridimensional, porque vai além dessa relação e existe (ou pode existir) como mulher. É capaz, ela própria, de se amar, o que 
subentende a capacidade de prosseguir como indivíduo, com carências e sonhos infindos, independentemente da condição de parideira. Inteira, porque capaz de amar os filhos e, no entanto, capaz de viver a própria vida, em termos individuais e profissionais.

\subsection{Ressignificação da identidade da mulher-mãe e ativismo digital}

Logo, com o passar dos anos, as mulheres adquirem alguns direitos, resultado de movimentos revolucionários. A partir da Revolução Francesa, no século XVIII, o feminismo ganha características de ação organizada, embora só conquiste roupagem política e transformadora nos anos 60 (século XX), com o revolucionário feminismo e o surgimento de pílulas contraceptivas que dão à mulher a necessária autonomia para escolher (ou não) a maternidade. Ademais, o controle das gestações afasta o sexo do fator de dominação do homem sobre a mulher, como visto em trechos de publicações clássicas, como as de Badinter (2000) e Sheehy (1986).

Ao tempo em que a maternidade sempre esteve e está ligada à construção social do ser mulher, desde a instalação gradativa do capitalismo e após as conquistas antes enunciadas, a mulher e/ou a mulher-mãe passam a ocupar espaços na vida pública, embora ainda carreguem o ranço das ciências biológicas, que tendem a associar o corpo da mulher ao corpo social. Essa imagem acaba por enfatizar a divisão desigual da mulher-mãe e do homem-pai. É preciso retirar essa condição biológica da mulher e sua consequente invisibilidade pública e privada em prol do cuidado à prole. Ao nascer um bebê, não nasce uma mãe. Ao contrário. Sua construção acontece desde a infância, com valores inofensivos e, ao mesmo tempo, perversos, espalhados por todos os lados e, principalmente, no imaginário feminino. É só lembrar Badinter (2000) e sua insistência em posicionar o amor entre mães e filhos ou entre filhos e mães como sentimento que exige conquista.

É, então, no início do século XXI, com a tão propalada revolução das tecnologias de informação e de comunicação (TIC), que a figura da mulher-mãe surge descontruída e empoderada em portais, sites, blogs, páginas eletrônicas, algumas das quais identificadas como "feministas e provocadoras", a exemplo da mantida pela jovem poeta indiana Rupi Kaur. As mais diversificadas redes sociais, que são, em sua essência, estruturas sociais que integram indivíduos e/ou instituições conectados por tipos de relações para o compartilhamento de informações, recorrendo, com frequência a aplicativos, difundem-se com celeridade. Dentre as redes com mais uso no Brasil, destacam-se twitter, facebook, instagram, linkedIn, YouTube, snapchat, Google+, pinterest, messenger e o WhatsApp.

Nesse momento, a problematização da maternidade ganha fôlego e conquista espaço. A mulher-mãe apropria-se do mundo virtual e institui, com força total, um novo espaço de luta para potencializar suas reivindicações não somente na esfera privada. Vai além e coloca no âmbito público, questões antes exclusivas do espaço privado: família, sexualidade, trabalho, divisão de tarefas em casa, cuidado com as crianças, oferta de creches para filhos pequenos, etc. Para Hall (2006, p. 45), tudo isso politiza "[...] a subjetividade, a identidade e o processo de identificação." Quer dizer, com as redes eletrônicas e as TIC em geral, a mulher-mãe lança mão de uma nova frente para sua atuação múltipla como ser humano, com vida individual e profissional, transformando os novos instrumentos em recursos relevantes para reforçar suas pelejas diárias e trazer novas temáticas para o debate social.

Tais questões resgatam velhas reivindicações e apontam para uma reconfiguração da postura da mulher-mãe, ou seja, para a ressignificação de sua identidade via ativismo digital. Agora, não mais como somente consumidora de informações/notícias. A figura materna utiliza-se dos meios digitais para produzir, ela mesma, conteúdos voltados, indistintamente, para o público feminino e masculino numa visão inter/pluri /multi /transdisciplinar. O dilema maior no processo de ressignificação identitária é conciliar a magia e o encantamento de gerar

Perspectivas em Gestão \& Conhecimento, João Pessoa, v. 8, n. 3, p. 20-39, set./dez. 2018. 
e/ou criar filhos sem renunciar a seu "eu", haja vista que, segundo Badinter (2000, p. 25), no caso da mulher, é impossível "[...] mencionar a figura da mãe na microssociedade familiar, sem alusão implícita ou explícita ao que ela chama 'dos dois outros'": pai e filho(s).

O protagonismo da mulher e da mulher-mãe, em particular, autoriza questionar a programação da mídia tradicional, desde novelas até anúncios publicitários, a exemplo da propaganda da Skol para o carnaval de 2015. À época, a campanha foca em mensagens como "Esqueci o 'não' em casa" e "Topo antes de saber a pergunta" em tom nitidamente sexista, com apologia subjacente ao estupro. De imediato, ativistas feministas ou mulheres conscientes do papel de agente social na sociedade hodierna iniciam movimento na Grande Rede. Compartilham fotos da publicidade da Skol com a contrarresposta "E trouxe o nunca", colando com fita isolante preta nos outdoors portadores da tal publicidade. Daí, a campanha é partilhada por milhares de pessoas no facebook e no instagram, por meio da exposição maciça das fotos da Skol, mas com ênfase para o revés.

A velocidade de transmissão e a simplicidade de manuseio e de publicação de informações na internet permitem apontar, com mais liberdade e maior rapidez, as fake news ou os equívocos não intencionais, reforçando as dúvidas que sempre cercam o universo digital, até porque, como Keen (2009) admite, muito se tem escrito sobre as benesses das inovações tecnológicas na sociedade da informação. As mudanças ocorridas em todos os setores do cotidiano do homem moderno incorporam ações triviais, como a ida ao banco ou à farmácia; intercâmbio de informações de cunho utilitário, como a experiência de ser mulher-mãe; até medidas burocráticas, como a prestação de contas como cidadão junto ao Fisco, são visíveis. Tudo tem o sabor de tecnologia, modernidade, avanço e evolução.

Porém, inovações, incluindo a internet, possuem um lado obscuro e cinza. A solidão humana acentua-se no momento em que o contato cara a cara dá lugar à proximidade forjada por trás de perfis cuidadosamente forjados em sites de relacionamento. Há o incremento da prostituição e de perversões sexuais. $O$ terrorismo ganha novo aliado. $O$ embuste editorial, idem; sem contar a nova forma de exclusão social, a chamada exclusão digital, que deixa à margem um montante de indivíduos em diferentes nações, por razões distintas. Aos fatores de ordem social, cultural, econômica e política, agrupam-se motivações de foro íntimo.

Por tudo isso, na ressignificação da identidade da mulher-mãe versus ativismo digital, é preciso atenção para que a maternidade (condição de ser mãe) nem relegue a importância da competência em informação (Colnfo) nem permaneça à mercê da interação tecnológica, seja no universo digital ou não. Ao contrário. As redes sociais devem propiciar voz e ação ao movimento das mulheres-mães, liberando sua expressão rumo à adesão de novos adeptos. É o acesso facilitado à informação graças às potencialidades da internet, tornando possível a construção e a solidificação de um "contra conteúdo" para ser propagado na Grande Rede, conforme Cunha (2012) menciona, ao tratar da contribuição do ciberativismo para o movimento de mulheres via o que denomina feminismo 2.0, e que comporta as reivindicações femininas e/ou feministas no espaço virtual em suas diferentes vitrinas, que expõem o ser mãe numa perspectiva de mundo real e, às vezes, sem o idealizado glamour.

Nesse sentido, são notórias as repercussões da internet nos movimentos existentes antes de sua emergência, reconfigurando estratégias e ações, e conduzindo à incrível expansão. Dentre tais movimentos, está o movimento feminista materno que adota as TIC para ampliar conquistas e fortalecimento. Como mencionado até então, por meio do ativismo digital, as mulheres, apoiadas em preceitos feministas, apropriam-se das mídias digitais com a finalidade precípua de debater as condições da mulher-mãe no espaço público e privado. Uma referência no âmbito da apropriação do ciberespaço - tal termo especifica tanto a infraestrutura material da comunicação digital quanto o universo oceânico de informações que ele abriga, assim como os seres humanos que navegam e alimentam esse universo - remete, no Brasil, a reflexões sobre maternidade presentes num dos blogs pioneiros Mothern 
(http://mothern. blogspot.com.br). Desde 2002, apresenta a maternidade inter-relacionada à sociedade de consumo e, hoje, circula também sob o formato de livros impressos e digitais, mantendo, porém, o propósito original das blogueiras em tratar da maternidade com leveza e humor, mas em tom realista, indo além da imagem de filhotes como "ursinhos carinhosos."

$\mathrm{Na}$ verdade, há muitos outros blogs voltados à maternidade. Dentre eles, o Google, como instrumento de busca, traz longa listagem, inclusive, estabelece um ranking no endereço https://www.trocandofraldas.com.br/20-blogs-de-maternidade, em território nacional e, praticamente, em todos os Estados. Entre muitos, exemplificam-se: http://agorasoumae.com.br; http://mamatraca.com.br; http://www.macetesdemae.com; http://www.maeclub.com.br; http://www.amaecoruja.com, com a curiosidade de que os próprios títulos são bem representativos dos propósitos das mães.

Não obstante a fragilidade inerente a dados estatísticos inerentes aos movimentos que circulam no espaço virtual, é interessante mencionar estudo recente que fornece ideia quantitativa acerca do ativismo digital materno $x$ competência em informação visando às transmutações da imagem da maternidade. No texto "100 BLOGS de mamãe e papai para você conhecer", 2017, o webinformado mapeia blogs específicos sobre maternidade, no Brasil, por meio de um estudo de inter-relacionamento de redes. Para tanto, utiliza técnicas estatísticas e a ferramenta IssueCrawler, a cargo da Digital Methods Initiative (DMI), Grupo de Pesquisa, que representa visível avanço sobre os métodos digitais de pesquisa da University of Amsterdam, século XVII. A IssueCrawler é um dos potentes softwares do Grupo, ao permitir mapear sites listados pelo público via técnica snowballing, designação traduzida em português como "amostra por bola de neve." Dentre as técnicas de amostragem não probabilística, identificase por permitir aos pesquisados iniciais convidarem novos partícipes de suas redes de relação, favorecendo o incremento da amostra e de sua representatividade.

A Figura 1 sinaliza o mapeamento da blogosfera materna gerado pelo referido soft, em que os círculos simbolizam os blogs, e as setas, os relacionamentos de redes.

Figura 1 - Mapeamento da rede de blogs de maternidade, Brasil, 2017

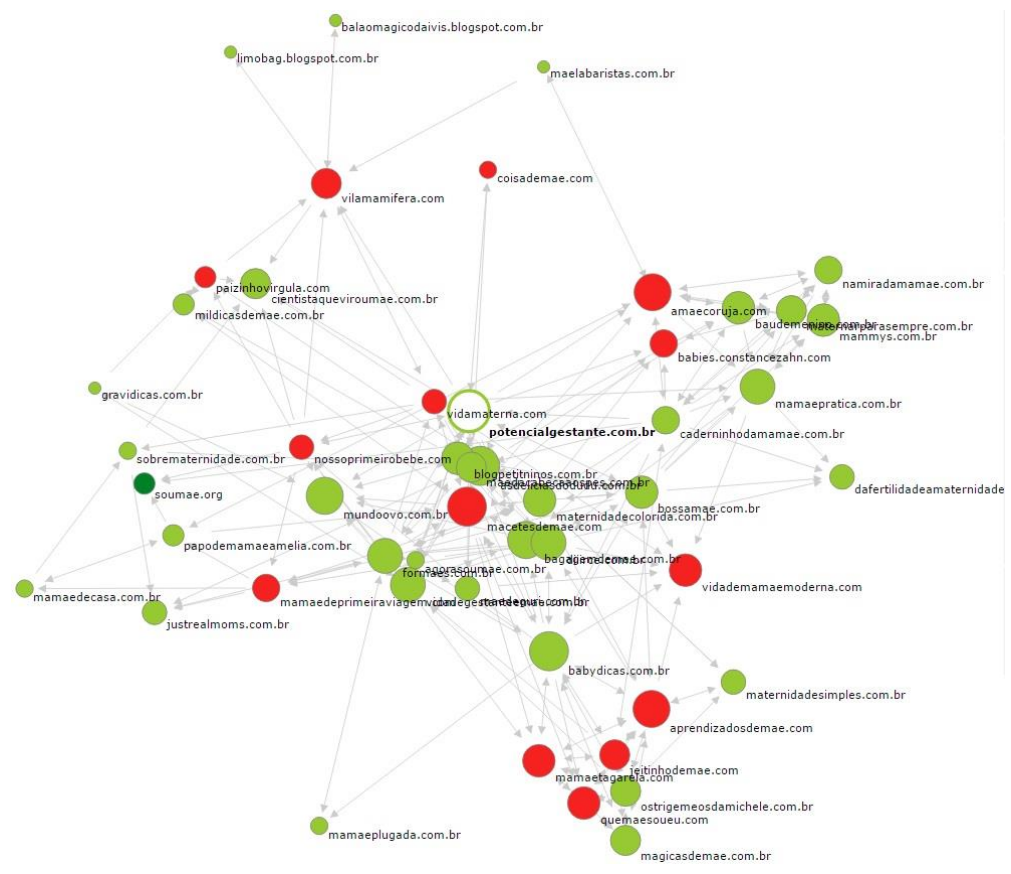

Fonte: 100 BLOGS de mamãe e papai para você conhecer" $(2017$, p. 2) 
Para maior compreensão acerca do trinômio - mulheres-mães; ativismo digital e competência em informação - vale a pena transcrever literalmente as instruções dos pesquisadores alemães, quando dizem:

1 - O tamanho do círculo está diretamente relacionado ao número de referências que o blog recebe na Rede. Quanto maior o círculo mais referenciado é o blog correspondente pelos seus pares. Referência aqui significa hyperlink de um blog para outro.

2 - A localização do círculo no esquema está diretamente relacionada ao posicionamento do blog em relação aos seus pares. Quanto mais central mais referenciado pelos blogs mais populares.

3 - A cor do círculo está relacionada com o tipo de domínio. A cor verde do círculo representa um blog em domínio ".com.br"; a cor vermelho [...] um blog em domínio ".com" e a cor verde escuro, [...] um blog em domínio ".org"

Assim, vê-se que enquanto os movimentos feministas expandem-se e adotam séria agenda de reivindicações voltada à conquista de garantias legais para suas causas, o ativismo digital, especificamente materno, investe para que seus direitos sejam reconhecidos tanto como questão jurídica quanto como questão social. Para Castells (1999), a inserção da problemática subjacente à condição de ser mãe na internet pode ser considerada, sim, um movimento social na Rede, uma vez que lança mão da autonomia disponível nos espaços simbólicos e virtuais. Complementando, Juris (2004) acresce que o espaço virtual surge como gigantesca vitrina, que comporta explanação de discursos, projetos e causas aliadas à transferência de dados, informações e, quiçá, conhecimentos a serem assimilados. Para esses autores, a internet resulta em eficaz difusão do movimento materno e recrutamento de aliados em diversas partes do globo.

Se, por um lado, o digital parece integrar-se em práticas e em modos de fazer ativismo preexistentes (ou pré-digitais), por outro lado, tal integração possui caráter transformador, à medida que gera novas gramáticas e novos repertórios de ação mediante a inserção e o suporte de ferramentas digitais. O digital participa de diferentes formas em cada uma das práticas que integram o trabalho ativista. Tais práticas vão da difusão de informações à mobilização e ao recrutamento, passando pela logística, propaganda, criação de redes e de eventos, enquanto sua importância e centralidade variam em cada uma das tarefas. De certo modo, certas atividades e/ou etapas do trabalho ativista beneficiam-se dos dispositivos e circuitos digitais, ao passo que outras se distanciam mais facilmente dessas ferramentas.

Portanto, o ativismo digital leva em conta seu alinhamento e seu engajamento nos procedimentos múltiplos de mudanças. Quanto maior o empenho, maior a chance de combater o que Sodré (2013) denomina de "infocontrole", para designar uma nova ordem de poder da imagem, com foco na continuação do sistema liberal. Em sua ótica, vivencia-se, agora, cada vez mais, uma nova ordem do poder da imagem, em que as TIC não são verdadeiramente instrumentos de democratização, e, sim, prolongamento do sistema neoliberal. Para tanto, é necessário que todos os envolvidos possuam competência crítica para filtrar aquilo que, de fato, é relevante ao movimento. Caso contrário, não será mais do que um sistema de informação submetido aos moldes do discurso determinista masculino.

Perspectivas em Gestão \& Conhecimento, João Pessoa, v. 8, n. 3, p. 20-39, set./dez. 2018. 


\section{COMPETÊNCIA EM INFORMAÇÃO: O PAPEL DA MULHER-MÃE}

Como exposto até então, a internet consiste em espaço repleto de possibilidades, haja vista seus maiores trunfos, quais sejam, interatividade, hipertextualidade, hipermídia e probabilidade de suprir demandas informacionais, de forma individualizada. A interatividade prevê oportunidades de participação do cidadão para expressar opiniões, votar, enviar produções em vídeo ou em outros suportes, embora essa aparente liberdade esbarre nos limites preestabelecidos por cada espaço eletrônico. A hipertextualidade vai além do texto em si e conduz a muitos outros em seus múltiplos desdobramentos. A convergência dos meios, por seu turno, inclui gráficos, sons, fotos, narração ou sequências animadas que caminham pari passu (TARGINO, 2009).

Segundo a autora supracitada, ambos, hipertexto e hipermídia consistem em método de organização não linear de informações, permitindo ao indivíduo selecionar o material que vai ler/ver/ouvir, quando e como, ao tempo em que estimula o aprofundamento de questões que surgem no decorrer da busca. $O$ acesso dispensa conhecimentos especializados e 0 próprio interessado manipula o sistema, graças às interfaces amigáveis homem $\mathrm{x}$ máquina: 0 leitor percorre caminhos diferenciados ainda que diante de um mesmo texto. Porém, para quem não tem familiaridade ou capacitação para utilizar os recursos de busca e recuperação da informação, o espaço cibernético representa ambiente informacional complexo.

Essa habilidade de pensamento não é ensinada nas escolas. Pelo contrário. 0 sistema educacional ensina a ler, fazer contas e seguir o padrão de interpretação do mundo, conforme estabelecido pelos princípios em vigor, mas não estimula a capacitação do indivíduo para o pensamento crítico em relação à filtragem das informações. Assim, inexiste aprendizado sobre o processo incessante e volumoso que caracteriza o fluxo informacional: como se informar e como transmitir informações, em meio à soma ilimitada de postagens disponibilizadas na internet em meio às fake news, o que justifica obras relativamente recentes que orientam leigos e profissionais em como enfrentarem o manancial de informações, à semelhança do livro "Fontes de informação na internet", 2009, organizado por Maria I. Tomaél, que, na esfera da $\mathrm{Cl}$, aponta facilidades para fortalecer a competência em informação.

A este respeito, vale reforçar que as mulheres-mães, em busca de sua competência em informação (Colnfo) frente a princípios básicos da $\mathrm{Cl}$, defrontam-se com um universo de informações, nem sempre úteis ou adequadas, reafirmando palavras fortes, mas precisas de Botelho (2018, p. 95) acerca da "outra face" das inovações tecnológicas:

A revolução digital, quando despontou na virada do milênio, parecia prenunciar a morte dos dogmatismos. O acesso às informações jamais fora tão universal; era lógico esperar que a humanidade se tornasse menos, e não mais, propensa ao autoengano. Mas não contávamos com as astúcias do fanatismo, essa força da natureza, que acha jeitos de renascer mesmo quando parece exorcizada. Facilidade de informação também é, tragicamente, facilidade de desinformação: jamais foi tão simples conferir um verniz plausível a ideias que contradizem a experiência.

E, na verdade, para a consecução do propósito mor das mulheres-mães em recorrerem ao ativismo digital materno como instrumento essencial de transformação da imagem da mulher-mãe - objetivo básico do estudo - trazendo a público seus anseios de fêmea e profissional, ao romper as fronteiras rígidas do lar sagrado, é imprescindível que se habilitem a filtrar as informações úteis às suas demandas, isto é, tornem-se competentes em informação.

A este respeito, de acordo com Dudziak (2003), acresce-se que a expressão information literacy foi introduzida pela primeira vez na literatura pelo norte-americano Paul

Perspectivas em Gestão \& Conhecimento, João Pessoa, v. 8, n. 3, p. 20-39, set./dez. 2018. 
Zurkowski, em 1974, em relatório apresentado à National Commission on Libraries and Informacion Science, em sua condição de presidente. O documento recomenda a instituição de um programa nacional para que todos os cidadãos alcançassem elevado nível da Colnfo.

Portanto, o termo em pauta - information literacy - refere-se à premência de se exercer domínio o mais completo possível ante a decantada explosão informacional, o que pressupõe habilidades e conhecimentos direcionados à busca, ao acesso, à organização, à avaliação e, por fim, à difusão do fluxo informacional e dos conhecimentos recém-gerados. Quer dizer, a information literacy é per se o cerne da competência em informação, como procedimento de interiorização dos elementos - habilidades e conhecimentos aliados a valores individuais e sociais - atrelados, sempre, à apreensão das informações em circulação para transmutação em conhecimento e, então, efetivação da aprendizagem (DUDZIAK, 2003).

Em linha similar de pensamento, Camila Araújo dos Santos (2017, p. 1), em síntese apresentada sobre sua recente tese de doutoramento, é enfática ao afirmar que a Colnfo atua como elemento transformador e inovador no processo de ensino-aprendizagem, ao promover

[...] nas pessoas a capacidade de obter uma visão crítica e holística sobre o mundo à medida que serve como instrumento de desenvolvimento integral da pessoa humana e de sua socialização mediante a formação de competências a fim de que não fiquem vulneráveis à manipulação, à discriminação, à distorção de valores, princípios e à injustiça e que possam exercer, a partir do uso inteligente e ético das informações, a cidadania plena.

Eis, pois, recursos vitais que favorecem às mulheres a chance plena de reflexão em torno do ativismo digital e sua relação com a competência em informação acerca da maternidade, em que pesem, como natural, a oposição de quem acredita que o termo competência opõe-se, de forma radical, à incompetência. Para a autora ora referendada,

[...] a competência está a serviço do indivíduo e daquilo que ele decide fazer com ela. Ela se desenvolve progressivamente, por meio de situações de aprendizagens, de modo a constituir um potencial que pode ser mobilizado quando há necessidade. A competência é um potencial "plural", pois requer a ativação de conexões, reflexões, avaliações, interpolações, de saberes múltiplos, de agir e intervir de maneira prática, a partir de aprendizados, para compreensão e intervenção crítica de uma situação (SANTOS, 2017, p. 1).

É evidente, pois, que distante do ostracismo e próxima de suas conquistas crescentes, a mulher-mãe possui potencialidades, que lhes permite expor seus pontos de vista, recorrendo a técnicas e ferramentas inovadoras, além de fontes fidedignas, como apontadas por Tomaél (2009) para agilizar a busca da informação compatível às suas demandas.

Os indivíduos que pretendem ser agentes de transformação e conquistar seu espaço na sociedade da informação necessitam adquirir habilidades específicas para o trato com a informação no que se refere à localização, ao acesso, ao uso, à comunicação e, principalmente, à geração de novos conhecimentos (HATSCHBACH, 2002, p. 10).

Segundo Araújo e Braga e Vieira (2010), levantamento realizado com pesquisadores brasileiros da $\mathrm{Cl}$ arrola, numa lista de 137 autores mencionados, Carol C. Kuhlthau como uma das estudiosas mais atuantes no avanço da information literacy e da Colnfo no campo da

Perspectivas em Gestão \& Conhecimento, João Pessoa, v. 8, n. 3, p. 20-39, set./dez. 2018. 
Ciência da Informação no país, constando dentre os 30 mais citados. No caso de Doyle (1994, p. 3), sua contribuição fortalece a fundamentação teórica que cerca a information literacy, ao sumarizar os atributos para uma pessoa (independentemente do gênero ou de ser mãe ou "pãe") ser considerada competente em informação. Eis os atributos:

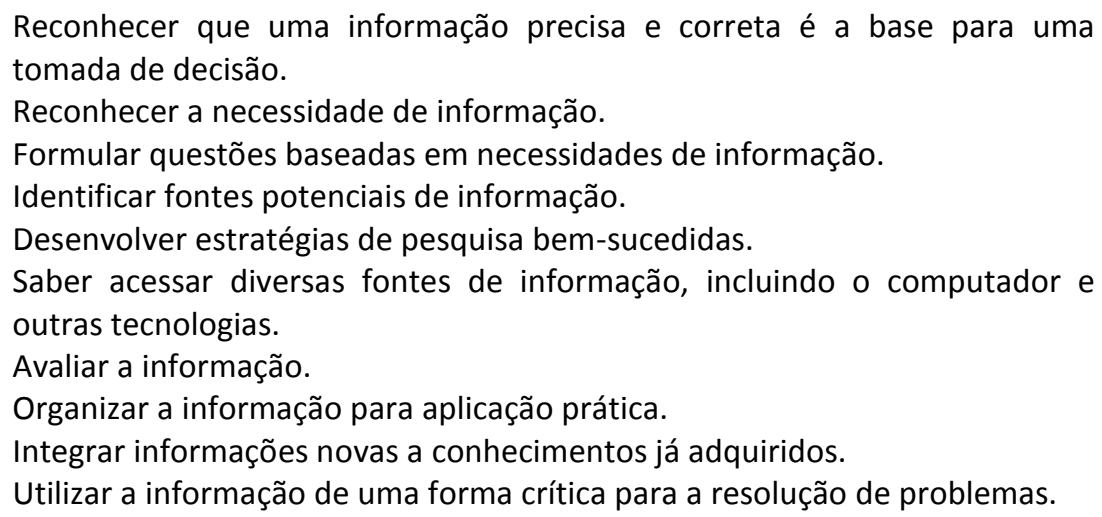

Com os atributos listados, observa-se que a Colnfo é integrada, relacionando os atributos gerais (conhecimentos, habilidades e atitudes) ao contexto no qual tais predicados vão ser empregados. A noção de competência em informação é, portanto, relacional, integrando habilidades do indivíduo e tarefas essenciais em determinada situação, isto é, a expressão é percebida à luz da possibilidade de ensino-aprendizagem. Provê condições necessárias para desenvolver nos sujeitos, mulheres ou homens, mães ou não, competências e os mencionados elementos - conhecimentos, habilidades e atitudes em informação que ainda não possuem -, com chance de incrementarem as que detêm. Logo, a competência em informação não se classifica como excludente - a discussão central não é "ser ou não ser" competente - mas desvendar o nível de competência de cada um, mediante "[...] ações diagnósticas e formativas de avaliação da Colnfo para que estratégias de ensino possam ser direcionadas de acordo com as potencialidades dos indivíduos" (SANTOS, 2017, p. 2).

Em síntese, o artigo adota o conceito de competência em informação próximo ao pensamento de Belluzzo (2001, p. 6), quando ressalta que a Colnfo se destaca dentro das competências em que o processo de ensino-aprendizagem conduzido por pessoas que querem aprender ao longo da vida é fundamental na era tecnológica e, então, "constitui-se na fluência científica e tecnológica e no saber utilizar a informação, criando novo conhecimento." Eis uma concepção na perspectiva de um conjunto de habilidades relacionadas às atividades de busca e recuperação da informação, descrito em quatro categorias:

1. Habilidade para buscar a informação demandada - conhecer as fontes de informação físicas (bibliotecas, centros de documentação, arquivos, etc.) ou virtuais (bibliotecas digitais e virtuais, portais, sites, blogs, páginas eletrônicas, redes sociais, listas de discussão, etc.).

2. Habilidade para filtrar a informação demandada - ser capaz de selecionar as informações relevantes e pertinentes às suas necessidades dentre o fluxo informacional excessivo, característica da sociedade da informação.

3. Habilidade para organizar a informação demandada - ser capaz de processar a informação para recuperá-la, quando necessário. 
4. Habilidade para utilizar as TIC - saber navegar no ciberespaço, assim como utilizar as potencialidades da internet, antes arroladas.

Como inevitável, essas habilidades devem vir acompanhadas de atitudes, como:

1. Estar aberto às inovações - o traço marcante da sociedade contemporânea é a liquidez, ou seja, as mudanças constantes e velozes.

2. Aprender a aprender - estar sempre disponível às atividades de aprendizagem.

3. Manter bom relacionamento nas equipes onde atua.

4. Estar alerta à educação continuada, consciente de que a sobrevivência no mercado de trabalho ou na convivência com os pares, exige de mães e pais, como de qualquer outro profissional, a assimilação de conhecimentos que se ampliam a cada dia.

No contexto da mulher-mãe, essas habilidades e atitudes são de suma importância para seu sucesso na sociedade da informação. Esta não se configura como modismo. Em sentido oposto, representa profunda mudança

[...] na organização da sociedade e da economia, havendo quem a considere um novo paradigma técnico-econômico. É um fenômeno global com elevado potencial transformador das atividades sociais e econômicas, uma vez que a estrutura e a dinâmica dessas atividades inevitavelmente serão, em alguma medida, afetadas pela infraestrutura de informações disponíveis (TAKAHASHI, 2000, p. 5).

E em meio a essas profundas transmutações sociais, culturais e tecnológicas, muitas mulheres-mães brasileiras, presumidamente, ainda não dominam, com segurança, o manejo informacional para exercer o ativismo digital. Porém, pela predisposição que se constata ao identificar páginas e mais páginas dedicadas à maternidade, é evidente que há busca desse segmento social em torno de aperfeiçoar suas habilidades informacionais nas mídias digitais, aproximando-as do alcance de um alto nível de competência em informação. Isto é, se, no caso da mulher-mãe no ativismo digital, a aquisição da Colnfo está em estágio de desenvolvimento, parcerias entre elas e outros profissionais, incluindo bibliotecários e cientistas da informação; docentes e tecnólogos; arquivistas e museólogos, enfim, profissionais de quaisquer outras áreas, dotados de competência em informação, decerto, trarão significativa contribuição e ganho para toda a coletividade.

A partir da premissa de que o conhecimento é indispensável para gerar conceitos, soluções e estruturas de compreensão, a mulher ativista em prol da maternidade necessita, como visto, coletar informações e interpretá-las para, a posteriori, torná-las instrumento facilitador para o uso. Como Nonaka e Takeuchi (1997) apontam, os conhecimentos são renováveis. Apoiam-se em conhecimentos preexistentes e em informações, levando em conta que o ensino-aprendizagem desenvolve-se dentre outros elementos contextuais e culturais. Dessa forma, a gestão da informação é salutar no contexto das mães no ativismo digital, de forma que se tornem competentes em informação e, como resultado, mais hábeis para tomar decisões importantes e socialmente responsáveis.

Perspectivas em Gestão \& Conhecimento, João Pessoa, v. 8, n. 3, p. 20-39, set./dez. 2018. 


\section{CONSIDERAÇÕES FINAIS}

É evidente que estudos desta natureza nem são conclusivos nem exaustivos. Envolvem conceitos complexos que demandam adaptação às realidades distintas, mesmo em território nacional, como também, maior divulgação e popularização em distintas instâncias, além de pesquisas complementares. Logo, inexiste pretensão de esgotar a discussão sobre o tema. Em linha oposta, o intuito é reduzir o estranhamento que ainda reste frente ao ativismo digital $x$ competência em informação, exercido por mães, embora direcionado aos gêneros em geral, contribuindo para discussões, em especial, no campo da $\mathrm{Cl}$.

Por ser uma categoria presente nas discussões sobre o feminismo, a maternidade acaba por não ser tratada como tema específico e relevante na $\mathrm{Cl}$, embora apareça, com certa regularidade em outros campos do conhecimento, a exemplo da psicologia e do serviço social. Entretanto, a maternidade carece de discussões com perspectivas mais refutadoras, que ampliem horizontes para o ser mãe e fortaleçam o movimento de ressignificação efetiva de sua identidade, sem desprezar a herança do feminismo, cujas fases são, sistematicamente, divididas e chamadas de "ondas".

Sem rigidez temporal, diz-se que a primeira "onda" acontece ao final do século XIX e avança até o início do século XX. Nessa fase, as mulheres, sobretudo na Inglaterra, organizamse para lutar por direitos básicos civis, dentre os quais o direito ao voto. A segunda "onda" inicia-se por volta de 1960 e se caracteriza como movimento de caráter libertário, reforçando Friedan (1963) e suas iniciativas. Ressaltam-se, nesse momento, alianças entre estudantes e operários e debates diretos sobre relações de poder entre homens e mulheres em prol de novo formato de relacionamento (heterossexual), no qual a mulher tenha liberdade e autonomia para decidir sobre seu corpo e sua vida.

A partir das décadas de 80 e/ou 90, inicia-se a terceira "onda." Traz à tona os paradigmas impostos pelas etapas anteriores e os aspectos essencialistas do feminismo, como o conceito de feminilidade. A luta por direito à terra, à saúde materna, contra o racismo e a favor das orientações sexuais das mulheres tornam-se efervescentes até atingir a quarta "onda", desta vez, marcada pelo ativismo digital ou, nas palavras de Cunha (2012), pelo feminismo 2.0, o qual permite expor à sociedade debates, antes restritos à esfera privada, reiterando Hall (2006).

Especificamente em relação ao ativismo materno digital, a competência em informação torna a mulher-mãe mais capacitada para, de fato, engajar-se ao movimento de valorização da maternidade. É o momento de discutir o ativismo digital materno no que concerne aos benefícios e às novas formas de ação e de lutas por meio da cibercultura, privilegiando a mobilização de mulheres-mães como intenso movimento nas redes sociais, momento quando se apropriam das sólidas potencialidades da internet e propõem um novo olhar sobre a maternidade na contemporaneidade. Diante da constatação de tantos e tantas páginas dedicadas à temática, acredita-se que as mulheres com filhos vêm vivenciando o intercâmbio de experiências graças à utilização da plataforma digital, confirmando, pois, a hipótese central do estudo que posiciona o ativismo digital materno como estratégia de mudança da imagem da mulher-mãe mediante a competência em informação e sua interrelação com o novo olhar que se vislumbra sobre o ser mãe:

[...] O desenvolvimento dessas tecnologias permite a ampliação dos ambientes sociais reais e a multiplicação de oportunidades para lidar com as informações disponíveis na sociedade. Isso favorece uma atividade extensiva em todas as regiões cerebrais, especialmente quando os sujeitos vasculham e buscam web pages, estimulando, em particular, a atividade nas

Perspectivas em Gestão \& Conhecimento, João Pessoa, v. 8, n. 3, p. 20-39, set./dez. 2018. 
regiões pré-frontais associadas à tomada de decisões e à resolução de problemas, dentre outras capacidades (AZEVEDO; GASQUE, 2017, p. 166).

É evidente que tal afirmativa aplica-se às mulheres-mães. No entanto, há um longo caminho a ser percorrido. Nenhuma inovação tecnológica é capaz de garantir por si só a ruptura do pensamento que dá suporte à dominação masculina. Como Scavone (2006, p. 48) chama atenção, as TIC podem atuar como espaço de "[...] reprodução de significados clássicos de gênero que contribuem para a permanência da relação e dominação." Afinal, a violência simbólica a que a mulher-mãe remonta a períodos remotos, como antes discutido, de tal forma que as mudanças ocorrem lentamente, o que exige romper o silêncio ante questões que propiciam nossa autoaprovação. Segundo palavras literais de Sheehy (1986, p. 479),

[...] uma das grandes recompensas da jornada pelo período desmantelante da renovação consiste em chegarmos a nos aprovar ética e moralmente, independentemente dos padrões e das agendas de outras pessoas. Ao deixarmos de lado o desejo de que nossos pais [e esposos] fossem diferentes, e, navegando, através de vários estilos de vida, até aquele ponto de dignidade que vale a pena defender, podemos alcançar [...] integridade [...] como aquele estágio final de desenvolvimento adulto, no qual damos o beneplácito à nossa própria vida.

Por fim, ao tempo em que as inferências confirmam a presença crescente das mulheres-mães nas redes sociais recorrendo às tecnologias como ferramenta para colocar a maternidade em pauta, há urgência de políticas públicas mais sólidas em prol dessas mulheres, de modo a que a competência em informação alcance outras mães. Há, ainda, um novo olhar, desta vez, em direção ao homem. Sem mais deter de forma peremptória o poder patriarcal de gerir a vida de mulheres e filhos e de decidir sobre bens patrimoniais e imateriais (FIDALGO, 2003), como a mídia impressa e digital da atualidade, vez por outra alerta, o homem parece atônito em busca de sua própria identidade e posição na tessitura social.

\section{REFERÊNCIAS}

ARAÚJO, C. A. Á.; BRAGA, R. M. de O.; VIEIRA, W. de Oliveira. A contribuição de C. Kuhlthau para a Ciência da Informação. Revista Digital em Biblioteconomia e Ciência da Informação, Campinas, v. 7, n. 2, p. 185-198, jan. / jun. 2010.

AZEVEDO, I. C. M. de; GASQUE, K. C. G. D. Contribuições dos letramentos digital e informacional na sociedade contemporânea. TransInformação, Campinas, v. 29, n. 2, p. 163173, maio/ago. 2017.

BADINTER, E. L'amour en plus. Paris: Flammarion, 2000.

BELLUZZO, R. C. B. A information literacy como competência necessária à fluência científica e tecnológica na sociedade da informação: uma questão de educação. In: SIMPÓSIO DE ENGENHARIA DE PRODUÇÃO DA UNESP, 7., 2001, São Paulo. Anais... São Paulo: UNESP, 2001. Disponível em: http://www.simpep.feb.br/ana8.html. Acesso em: 3 jan. 2018.

BERGER, P. L.; LUCKMANN, T. A construção social da realidade: tratado de sociologia do conhecimento. Petrópolis: Vozes, 2004.

Perspectivas em Gestão \& Conhecimento, João Pessoa, v. 8, n. 3, p. 20-39, set./dez. 2018. 
BOTELHO, J. F. A lição de Pirro para 2018. Veja, São Paulo, ano 51, n. 1, p. 95, 3 jan. 2018.

CAPURRO, R. Epistemologia e Ciência da Informação. In: ENCONTRO NACIONAL DE PESQUISA EM CIÊNCIA DA INFORMAÇÃO, 5., 2003. Belo Horizonte. Anais... Belo Horizonte: UFMG, 2003.

CASTELLS, M. A. Sociedade em rede. São Paulo: Paz e Terra, 1999.

100 BLOGS de mamãe e papai para você conhecer. 2017. Disponível em: http:// webinformado.com.br/blogs-de-maternidade. Acesso em: 4 abr. 2018.

CUNHA, C. Feminismo 2.0: a contribuição do ciberativismo para o movimento de mulheres e a importância do marco civil da internet. 2012. Disponível em: http://feminismo-2-0-acontribuicao-do-ciberativismo-para-o-movimento-de-mulheres-e-a-importancia-do-marcocivil-da-internet. Acesso em: 13 fev. 2018.

DOYLE, C. S. Information literacy in an information society: a concept for the information age. ERIC Clearinghouse on Information \& Technology, New York, 1994.

DUDZIAK, E. A. Information literacy: princípios, filosofia e prática. Ciência da Informação, Brasília, v. 32, n. 1, p. 23-35, jan. / abr. 2003.

ESPÍRITO SANTO, P. Os estudos de gênero da Ciência da Informação. Em Questão, Porto Alegre, v. 14, n. 2, p. 317-332, jul. / dez. 2008.

FIDALGO, L. (Re)construir a maternidade numa perspectiva discursiva. Lisboa: Instituto Piaget, 2003.

FLORES, F.; BALAGO, R. Conheça pais que conciliam filhos e hobbies como escalar o Himalaia e ir a shows do Iron Maiden. 2017. Disponível em: http://www1.folha.uol.com. br/saopaulo/2017/08/ 1907231-conheca-pais-que-conciliam-filhos-e-hobbies-como-escalar-ohimalaia-e-ir-a-shows-do-iron-maiden.shtml. Acesso em: 13 fev. 2018.

FRIEDAN, B. The feminine mystique. New York: W. W. Norton and Co.,1963.

GIL, A. C. Como elaborar projetos de pesquisa. 5. ed. São Paulo: Atlas, 2010.

HALL, S. A identidade cultural na pós-modernidade. 11. ed. Rio de Janeiro: DP\&A, 2006.

HATSCHBACH, M. H. de L. Information literacy: aspectos conceituais e iniciativas em ambiente digital para o estudante de nível superior. 2002. 108 f. Dissertação (Mestrado em Ciência da Informação) - Escola de Comunicação, Universidade Federal do Rio de Janeiro, Rio de Janeiro, 2002.

JENKINS, H. Cultura da convergência. 2. ed. São Paulo: Aleph, 2009.

JURIS, J. Indymedia: de la contra-información a la utopía informacional. In: SÁEZ, V. M. (Coord.). La Red es de todos: cuando los movimientos sociales se apropian de la red. Madrid: Ed. Popular, 2004.

Perspectivas em Gestão \& Conhecimento, João Pessoa, v. 8, n. 3, p. 20-39, set./dez. 2018. 
KEEN, A. The cult of the amateur: how today's internet is killing our culture. 2nd ed. New York: The Doubleday Broadway Publ., 2009.

LÉVY, P. Cibercultura. 2. ed. São Paulo: Ed. 34, 2000.

NONAKA, I.; TAKEUCHI, H. Criação de conhecimento na empresa: como as empresas japonesas geram a dinâmica da inovação. 8. ed. Rio de Janeiro: Campus, 1997.

PROGRAMA DAS NAÇÕES UNIDAS PARA O DESENVOLVIMENTO (PNUD). Relatório sobre o desenvolvimento humano no Brasil: 1996. Brasília: IPEA, 1996. 186 p.

RIBEIRO, A. Mamães paulistanas contam como a maternidade transformou suas vidas. 2017. Disponível em: http://www1.folha.uol.com.br/saopaulo/2017/05/1881386-mamaespaulistanas-contam-como-a-maternidade-transformou-suas-vidas.shtml. Acesso em: $13 \mathrm{fev}$. 2018.

SANTOS, C. A. dos. O protagonismo social da competência em informação (Colnfo). Out. 2017. Disponível em: https://www.ofaj.com.br/colunas conteudo.php?cod=1089. Acesso em: 3 mar. 2018.

SCAVONE, L. Novas tecnologias conceptivas: teorias e políticas feministas. In: FERREIRA, V.; ÁVILA, M. B.; PORTELLA, A. P. (Org.). Feminismo e novas tecnologias reprodutivas. Recife: SOS Corpo, 2006.

SHEEHY, G. Passages: predictable crises of adult life. New York: Bantam Books, 1986.

SODRÉ, M. Antropológica do espelho: uma teoria da comunicação linear e em rede. 4. ed. Petrópolis: Vozes, 2013.

STUDART, H. Mulher objeto de cama e mesa. 22. ed. Petrópolis: Vozes, 1990.

STUMPF, I. R. C. Pesquisa bibliográfica. In: DUARTE, J.; BARROS, A. T. de. Métodos e técnicas de pesquisa em comunicação. 8. reimpressão. São Paulo: Atlas, 2008. p.51-61.

TAKAHASHI, T. (Org.). Sociedade da informação no Brasil: livro verde. Brasília: MCTIC, 2000.

TARGINO, M. das G. Internet: ante isto e depois disto, o jornal, onde fica? In: TARGINO, M. das G.; CASTELO BRANCO, S.; CARVALHO, C. P.; MAGALHÃES, L. (Org.). Comunicação, educação e cultura na era digital: Intercom Nordeste 2009. Teresina: EDUFPI, 2009. p. 120-143.

TOMAÉL, M. I. (Org.). Fontes de informação na internet. Londrina: EDUEL, 2009. 184 p. p. 328. 